\title{
Remission of nephrotic syndrome after surgical intervention for bronchogenic carcinoma: the I0-year follow-up of a patient with membranous nephropathy
}

This article was published in the following Dove Press journal: International Medical Case Reports Journal

\author{
Izumi Nagayama' \\ Tetsu Akimoto ${ }^{1,2}$ \\ Yuko Ono ${ }^{3}$ \\ Yoshihiko Ueda ${ }^{3}$ \\ Daisuke Nagata' \\ 'Division of Nephrology, Department \\ of Internal Medicine, Jichi Medical \\ University, Shimotsuke, Tochigi, Japan; \\ ${ }^{2}$ Department of Chronic Kidney \\ Disease Pathophysiology, Jichi Medical \\ University, Shimotsuke, Tochigi, Japan; \\ ${ }^{3}$ Department of Pathology, Dokkyo \\ Medical University Saitama Medica \\ Center, Koshigaya, Saitama, Japan
}

Correspondence: Tetsu Akimoto Division of Nephrology, Department of Internal Medicine, Jichi Medical University, 33|I-I Yakushiji, Shimotsuke,

Tochigi 329-0498, Japan

$\mathrm{Tel}+8 \mathrm{I} 285587346$

Fax +8I 285444869

Email tetsu-a@jichi.ac.jp

\begin{abstract}
Nephrotic syndrome (NS) is a pivotal manifestation of glomerular injury associated with various types of neoplasms. It may either precede or act as the presenting feature of the disease, whereas membranous nephropathy $(\mathrm{MN})$ is a major phenotype of paraneoplastic glomerulopathies. However, there is a lack of information regarding the remission from paraneoplastic NS due to MN in patients who achieve favorable long-term survival after the successful removal of malignant tissue. We, herein, describe a case of biopsy-proven $\mathrm{MN}$ in a 65-year-old male patient with bronchogenic carcinoma, which was found during the systemic workup for concurrent NS. He was successfully treated with thoracoscopic left lower lobectomy and achieved a complete remission from NS at approximately 10 months after radical surgery. In 10 years of follow-up, there has been no recurrence of the pulmonary cancer and the patient is doing well with no relapse of NS, despite having never received treatment with any type of immunomodulating agent. Several concerns, including diagnostic management and therapeutic strategies for paraneoplastic NS, are discussed.
\end{abstract}

Keywords: nephrotic syndrome, paraneoplastic kidney disease, membranous nephropathy, pulmonary cancer, remission

\section{Introduction}

Nephrotic syndrome (NS) is a pivotal manifestation of the glomerular injury associated with various types of neoplasms. ${ }^{1}$ It may either precede or act as the presenting feature of the diseases, whereas membranous nephropathy (MN), one of the common kidney injuries leading to adult-onset NS, develops as a major phenotype of paraneoplastic glomerulopathies among some subsets of patients with solid tumors., ${ }^{2,3}$ Although the link between cancer and glomerular injury has been studied by multipronged approaches, ${ }^{4-7}$ the information about the prognosis of patients with this disease state remains insufficient. In this report, we describe a case of $\mathrm{NS}$ due to $\mathrm{MN}$ in a male patient complicated by bronchogenic carcinoma. The patient's NS remained in remission for at least 10 years after radical surgery for the malignancy. Several concerns relevant to the diagnostic and management approaches of paraneoplastic NS due to $\mathrm{MN}$ are also discussed.

\section{Case report}

A 65-year-old man with a history of a coronary artery disease and hyperlipidemia was referred to our unit because of proteinuria $(2+)$, which had been found by his primary 
physician a few weeks previously. He had a 60-pack-year history of cigarette smoking, but had quit smoking 13 years previously when he underwent percutaneous coronary intervention for acute myocardial infarction. Thereafter, he was treated with aspirin and pravastatin sodium; no remarkable cardiac episodes were subsequently noted. At the referral, he was found to have a reduced serum albumin (sAlb) level of $3.7 \mathrm{~g} / \mathrm{dL}$ with a urine protein-to-creatinine $(\mathrm{Cr})$ ratio of 4.3 $\mathrm{g} / \mathrm{gCr}$, despite having no apparent history of renal disease. A chest radiograph showed a round well-circumscribed solitary lesion in the middle zone of the left lung (Figure 1A). A subsequent chest computed tomography (CT) examination showed a solid mass in the lower lobe posterior segment without any findings of lymphadenopathy (Figure 1B). His hypoalbuminemia gradually progressed during the next 5 weeks. He was, therefore, admitted to our hospital for further workup.

A physical examination at the admission was unremarkable, with the exception of leg edema. His blood pressure was $118 / 60 \mathrm{mmHg}$ with a pulse of 62 beats/min and a body temperature of $36.1^{\circ} \mathrm{C}$. No rashes or petechiae were observed. Renal sonography revealed that the right and left kidney long axis dimensions were 12.2 and $11 \mathrm{~mm}$, respectively, with normal renal cortex echogenicity. The laboratory data on admission are summarized in Table 1. Tests for hepatitis B virus surface antigens and antibodies to the hepatitis $C$ virus were negative. A 24-hour urine specimen contained $4.8 \mathrm{~g}$ of protein. His proteinuria selectivity index and $\mathrm{Cr}$ clearance were 0.22 and $104.8 \mathrm{~mL} / \mathrm{min}$, respectively. A diagnosis of NS accompanied by a presumed left lung neoplasm was made. Although no findings compatible with malignant tissue were confirmed by a transbronchial lung biopsy performed on hospital day 5 , concurrent bronchial washing and brushing cytology specimens showed class IV atypical smears. On hospital day 10, a renal biopsy was performed (Figure 2), which revealed 3 cores of renal parenchyma with 17 glomeruli, 2 of which

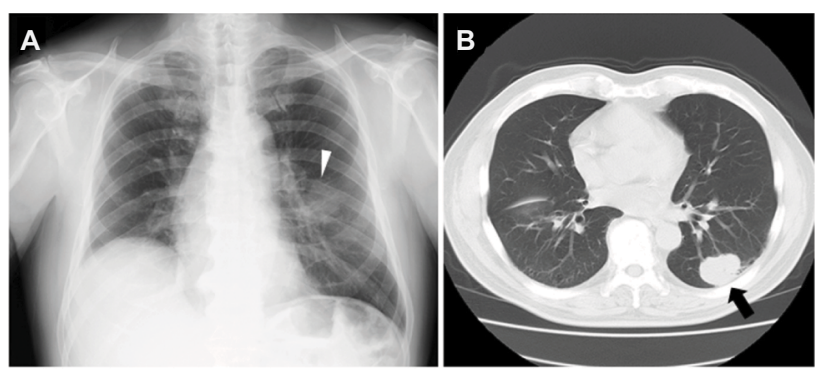

Figure I The radiographic findings.

Notes: A conventional chest radiograph showing a solitary circular opacity (white arrowhead) in the mid-zone of the left lung (A). A chest CT image shows a wellmarginated soft tissue nodule in the left lower lobe posterior segment (black arrow). A $48 \times 45 \times 30-\mathrm{mm}^{3}$ moderately differentiated squamous cell carcinoma was found during surgery (B). were globally sclerotic. The rest of the glomeruli exhibited an almost normal appearance, and marginal tubular atrophy was noted. Although immunofluorescence staining showed sparse and partial but not diffuse peripheral deposition of IgG, scattered electron-dense deposits on the subepithelial zone of the basement membrane were noted on electron microscopy, encouraging us to ascribe his NS to MN stage I. The patient consequently underwent thoracoscopic left lower lobectomy combined with systemic lymphadenectomy on hospital day 26 , leading to a diagnosis of stage IB (T2NOM0) squamous cell carcinoma of the lung in accordance with the American Joint Committee on cancer tumor-node-metastasis classification (6th edition). ${ }^{8}$ The patient's postoperative recovery was uneventful, and the serum cytokeratine-19 fragments (CYFRA) level promptly settled to approximately $1.7 \mathrm{ng} /$ $\mathrm{mL}$. He was not treated with steroids or any other immunosuppressive agents; however, his peripheral edema gradually disappeared over a 1-month period; the normalization of the reduced sAlb levels lagged behind for an additional 2 months. Finally, the patient achieved a complete remission from the $\mathrm{NS}$ with a reduced urine protein to $\mathrm{Cr}$ ratio of $0.21 \mathrm{~g} / \mathrm{gCr}$ at approximately 10 months after the surgery (Figure 3 ). In 10 years of follow-up, there has been no recurrence of the pulmonary cancer, and the patient is doing well with steady

Table I The laboratory data on admission

\begin{tabular}{lll}
\hline White blood cells & $7,300 / \mu \mathrm{L}$ & $(3,900-9,800)$ \\
$\mathrm{Hb}$ & $16.0 \mathrm{~g} / \mathrm{dL}$ & $(13.5-17.6)$ \\
Platelet count & $24.0 \times 10^{4} / \mathrm{\mu L}$ & $(13.0-36.9)$ \\
Fibrinogen & $482 \mathrm{mg} / \mathrm{dL}$ & $(129-27 \mathrm{I})$ \\
Blood urea nitrogen & $14 \mathrm{mg} / \mathrm{dL}$ & $(8-20)$ \\
$\mathrm{Cr}$ & $0.84 \mathrm{mg} / \mathrm{dL}$ & $(0.63-1.03)$ \\
Total protein & $6.7 \mathrm{~g} / \mathrm{dL}$ & $(6.9-8.4)$ \\
Albumin & $3.0 \mathrm{~g} / \mathrm{dL}$ & $(3.9-5.1)$ \\
Sodium & $139 \mathrm{mmol} / \mathrm{L}$ & $(136-148)$ \\
Potassium & $4.5 \mathrm{mmol} / \mathrm{L}$ & $(3.6-5.0)$ \\
Chloride & $104 \mathrm{mmol} / \mathrm{L}$ & $(96-108)$ \\
Calcium & $8.7 \mathrm{mg} / \mathrm{dL}$ & $(8.8-10.1)$ \\
Phosphorus & $2.6 \mathrm{mg} / \mathrm{dL}$ & $(2.4-4.6)$ \\
C-reactive protein & $0.12 \mathrm{mg} / \mathrm{dL}$ & $(0-0.14)$ \\
IgG & $1,209 \mathrm{mg} / \mathrm{dL}$ & $(870-1,700)$ \\
lgA & $304 \mathrm{mg} / \mathrm{dL}$ & $(110-410)$ \\
IgM & $94 \mathrm{mg} / \mathrm{dL}$ & $(33-160)$ \\
C3 & $158 \mathrm{mg} / \mathrm{dL}$ & $(86-160)$ \\
C4 & $40 \mathrm{mg} / \mathrm{dL}$ & $(17-45)$ \\
Squamous cell carcinoma-related antigen & $1.4 \mathrm{ng} / \mathrm{mL}$ & $(<2.1)$ \\
Carcinoembryonic antigen & $1.7 \mathrm{ng} / \mathrm{mL}$ & $(<4.5)$ \\
CAI9-9 & $34 \mathrm{U} / \mathrm{mL}$ & $(<36)$ \\
CYFRA & $4.6 \mathrm{ng} / \mathrm{mL}$ & $(<3.5)$ \\
\hline
\end{tabular}

Notes: The reference ranges for each parameter used at our institute (jichi Medical University Hospital) are indicated in the parentheses.

Abbreviations: CA, cancer antigen; $\mathrm{Cr}$, creatinine; CYFRA, cytokeratin-19 fragments; $\mathrm{Hb}$, hemoglobin; lg, immunoglobulin. 


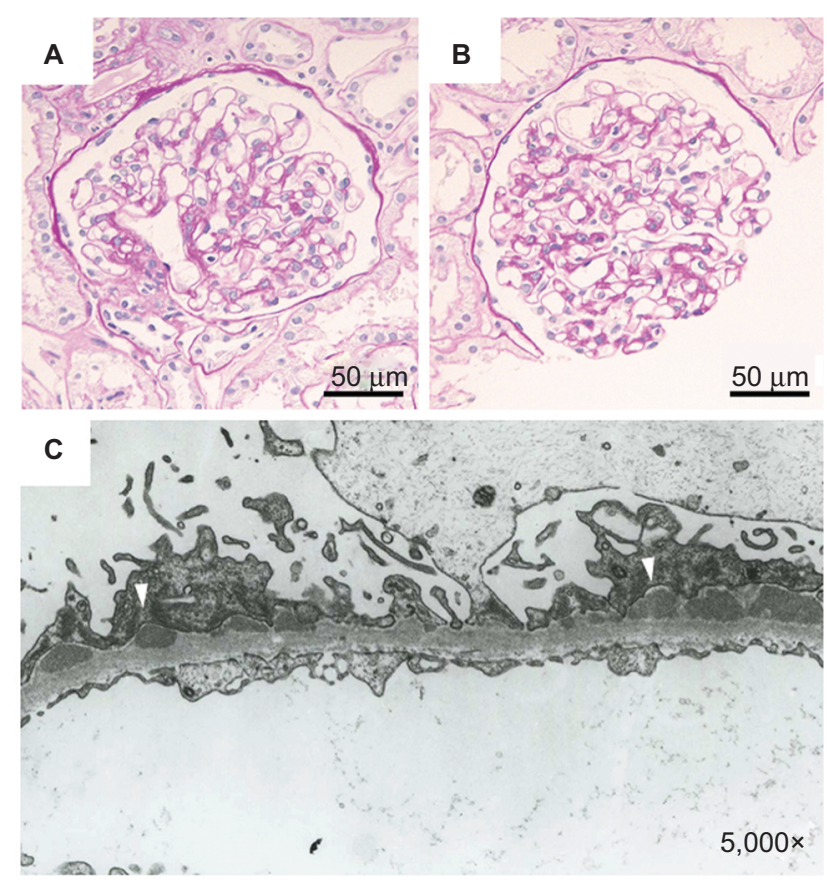

Figure 2 The renal biopsy findings.

Notes: Light micrographs of the glomeruli in different portions of the renal biopsy core (A and $\mathbf{B}$ ) indicate the glomeruli with no apparent structural abnormalities (Periodic acid-Schiff staining). The glomerular capillaries are patent, and the basement membranes are delicate. An electron micrograph of a portion of the glomerulus (C) shows scattered segmental subepithelial electron-dense deposits (arrowheads) without distinct intervening spikes. The scale or scale bar is indicated in each panel.

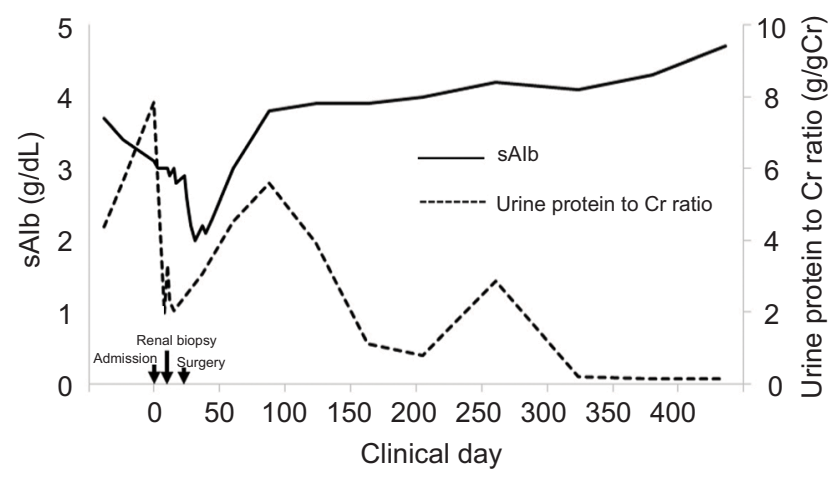

Figure 3 Serial changes in sAlb and urine protein before and after thoracoscopic left lower lobectomy.

Notes: The number " 0 " is designated as the point of admission. Note that the patient's NS reached complete remission at approximately 10 months after the surgery.

Abbreviations: $\mathrm{Cr}$, creatinine; NS, nephrotic syndrome; sAlb, serum albumin.

serum Cr levels ranging from 0.8 to $0.9 \mathrm{mg} / \mathrm{dL}$; furthermore, there has been no relapse of NS.

\section{Discussion}

The clinical scenario of the current patient, characterized by a set of conditions including NS due to $\mathrm{MN}$ and pulmonary malignancy, may not be surprising. ${ }^{1-3}$ However, we strongly recommend accumulating further cases that are similar to ours, as this would allow us to determine how to deal with patients whose cases are complicated by paraneoplastic glomerulopathies. Furthermore, it would reveal more information about the overall prognosis of patients with the disease, which remain challenging in the fields of oncology and nephrology.

The list of paraneoplastic glomerulopathies includes a number of glomerular diseases, such as MN, minimal change disease, membranoproliferative glomerulonephritis, rapidly progressive glomerulonephritis, focal segmental glomerulosclerosis, and immunoglobulin A (IgA) nephropathy. Furthermore, solid tumor-associated MN and Hodgkin lymphoma-related minimal change disease have received focus as classic phenotypes of this clinical entity. ${ }^{2,3}$ It may be difficult to precisely determine their relative frequency because of several confounding variables, such as potential selection bias and demographic characteristics of the populations, although the most common glomerulopathy reported thus far is $\mathrm{MN},{ }^{2,3,9}$ and the remaining diseases have been reported less frequently. ${ }^{2}$

The malignancies most frequently associated with glomerulopathies are adenocarcinomas of the lung and gastrointestinal tract.,3,9 Numerous other malignant diseases can be involved as well; however, paraneoplastic glomerular diseases are rarely linked to breast cancer despite the high incidence of this neoplasm. ${ }^{9}$ Some of these trends can also be seen in patients with paraneoplastic MN.,3,10 Indeed, a wide variety of neoplasms have been associated with $\mathrm{MN}$, with lung and gastric carcinomas being the most common. ${ }^{2,3}$ Other cancers reported to be associated with the disease are thymoma, renal cell, prostate, colorectal, pancreatic, esophageal, and hepatic carcinomas. ${ }^{3,11}$ Even a link between $\mathrm{MN}$ and breast cancer has been acknowledged. ${ }^{3,11}$ Although these 2 conditions often manifest themselves within 12 months of each other, ${ }^{9,11}$ a neoplastic disease may appear even years after the diagnosis of $\mathrm{MN}$ has been made. ${ }^{12,13}$ This fact has encouraged us to explore the potential existence of underlying but as yet undisclosed neoplasia that later may be detected. ${ }^{12}$ Although the diagnosis of pulmonary carcinoma in our patient was straightforward, the main concern is to determine how thorough the search should be in subjects with the disease. ${ }^{1,9,12}$ Experts have recommended that basic routine cancer screening procedures, including chest radiography, an occult blood survey of stool specimens, colonoscopy, and the measurement of carcinoembryonic antigen, be included in the diagnostic evaluation - especially in elderly patients with newly developed MN without any other obvious causes. ${ }^{1,9,12,14}$ 
As sex-specific surveys, the measurement of the prostatespecific antigen level, a careful breast examination, a mammogram, and cervical cytology should be performed, while further investigations, including bronchoscopy, gastroscopy, and CT, may be in order after the first-line assessment. ${ }^{9,12,14}$ Some of these investigations are practiced empirically in the ordinary clinical settings; however, the extent of the workup would vary depending on the context. ${ }^{1,15,16}$ Otherwise, we may need to focus on the recent landmark studies demonstrating the diagnostic impact of anti-phospholipase A2-receptor (anti-PLA2) autoantibodies, which have received focus as a pathognomonic indicator of idiopathic $\mathrm{MN},{ }^{17,18}$ although these can occasionally be seen in patients with other glomerular diseases as well. ${ }^{18,19}$ It should also be noted that glomerular immune deposits in cancer-associated MN are often IgG1 or IgG2 subclass-dominant. ${ }^{20}$ Consequently, the testing of anti-PLA2 autoantibodies and an IgG class-specific immunofluorescence analysis may be beneficial - when applicable - for determining whether MN has an underlying malignant cause, ${ }^{12}$ although such procedures were not available during the diagnostic workup of the patient described in this report.

Decisions on the treatment for neoplasm-associated renal disease should be based on the patient's general condition, and management strategies are sometimes complicated ${ }^{15}$ thus, it is not necessarily surprising that the optimal treatment remains to be established. However, the surgical removal of the tumor bulk may lead to remission from the renal manifestations in some subsets of patients with paraneoplastic kidney injury, ${ }^{4,5,21-23}$ and radiotherapy as well as chemotherapy can also be an attractive therapeutic option for patients with advanced unresectable neoplastic disease..$^{15,24-26}$ On the other hand, it has been recommended that the administration of immunosuppressive agents be avoided when treating $\mathrm{MN}$ because they may exacerbate the concurrent malignancy. ${ }^{2,14}$ However, it should be noted that there have been few systemic studies on this topic and some anecdotal examples have indicated that the use of corticosteroids does not necessarily induce adverse events, ${ }^{21,27,28}$ implying the need for the careful validation of this policy.

The relationship between the glomerulopathy and neoplasia may be indicated by clinical characteristics, such as a close temporal link and parallel evolution, including improvement, resolution, and relapse..$^{1-3,9,12,15}$ However, we should bear in mind that the interval between the successful treatment of a neoplasm and remission from NS can often be months to years. ${ }^{1,4,9,14}$ Given the fact that spontaneous remission of NS due to idiopathic MN usually occurs after 18-23 months, ${ }^{29}$ there may be occasional difficulties in distinguishing between the disease that occurs secondary to malignancy and the primary form of the disease. Although our patient did not fulfill the criteria described above, the distinct reduction of proteinuria that was confirmed within 10 months after surgery strongly encourages us to couple the kidney disorder mechanistically with the pulmonary carcinoma. Currently, there is only limited information on the remission from NS due to paraneoplastic glomerulopathies and long-term survival after the successful removal of neoplasms; ${ }^{4,5,9}$ however, there is an anecdotal report that describes a case of NS associated with gastric carcinoma in which subtotal gastrectomy was successful in relieving both conditions for at least 10 years. ${ }^{30}$ Perhaps, this is because the many of the malignancies associated with the disease are often advanced and/or incurable at the time of diagnosis., ${ }^{2,9,21}$ Indeed, the prognosis of these patients has been shown to be grave: among 44 patients whose clinical courses were disclosed, 34 (77\%) died within a relatively short time span with a median survival of 12 months from the onset of their renal manifestations; only 7 of the 34 survived for $>2$ years. ${ }^{31}$ We hope that the present case will serve as an illustrative example of a successfully managed paraneoplastic kidney disease associated with a favorable prognosis resulting from a prompt surgical intervention.

\section{Acknowledgment}

This study was supported in part by a Grant-in-Aid for Research on Advanced Chronic Kidney Disease, Practical Research Project for Renal Diseases from the Japan Agency for Medical Research and Development (AMED), and by a grant for Private University Research Branding Project from the Ministry of Education, Science and Culture, Japan. Written informed consent was obtained from the patient for the publication of this case report and any accompanying images.

\section{Disclosure}

TA is affiliated with an endowed department supported by Terumo Co., Chugai Pharmaceutical Co., Ltd., and Kyowa Hakko Kirin Co., Ltd. The authors report no other conflicts of interest in this work.

\section{References}

1. Akimoto T, Otani N, Takeshima E, Saito O, Kusano E, Nagata D. Do we have to perform a renal biopsy? Clinical dilemmas in a case with nephrotic syndrome. Clin Med Insights Case Rep. 2014;7:67-70.

2. Bacchetta J, Juillard L, Cochat P, Droz JP. Paraneoplastic glomerular diseases and malignancies. Crit Rev Oncol Hematol. 2009;70(1):39-58.

3. Lien YH, Lai LW. Pathogenesis, diagnosis and management of paraneoplastic glomerulonephritis. Nat Rev Nephrol. 2011;7(2):85-95.

4. Pai P, Bone JM, McDicken I, Bell GM. Solid tumour and glomerulopathy. $Q J M .1996 ; 89(5): 361-368$. 
5. Lefaucheur C, Stengel B, Nochy D, et al. Membranous nephropathy and cancer: epidemiologic evidence and determinants of high-risk cancer association. Kidney Int. 2006;70(8):1510-1517.

6. Takeda SI, Chinda J, Murakami T, et al. Development of features of glomerulopathy in tumor-bearing rats: a potential model for paraneoplastic glomerulopathy. Nephrol Dial Transplant. 2012;27(5):1786-1792.

7. Leeaphorn N, Kue-A-Pai P, Thamcharoen N, Ungprasert P, Stokes MB, Knight EL. Prevalence of cancer in membranous nephropathy: a systematic review and meta-analysis of observational studies. Am J Nephrol. 2014;40(1):29-35.

8. Lung. In: Greene FL, Page DL, Fleming ID, et al, editors. AJCC Cancer Staging Manual. 6th ed. New York: Springer-Verlag; 2002:167-177.

9. Ronco PM. Paraneoplastic glomerulopathies: new insights into an old entity. Kidney Int. 1999;56(1):355-377.

10. Jhaveri KD, Shah HH, Calderon K, Campenot ES, Radhakrishnan J. Glomerular diseases seen with cancer and chemotherapy: a narrative review. Kidney Int. 2013;84(1):34-44.

11. Burstein DM, Korbet SM, Schwartz MM. Membranous glomerulonephritis and malignancy. Am J Kidney Dis. 1993;22(1):5-10.

12. Glassock RJ. Attending rounds: an older patient with nephrotic syndrome. Clin J Am Soc Nephrol. 2012;7(4):665-670.

13. Bjørneklett R, Vikse BE, Svarstad E, et al. Long-term risk of cancer in membranous nephropathy patients. Am JKidney Dis. 2007;50(3):396-403

14. Jefferson JA, Couser WG. Therapy of membranous nephropathy associated with malignancy and secondary causes. Semin Nephrol. 2003;23(4):400-405.

15. Ito C, Akimoto T, Nakazawa E, et al. A case of cervical cancer-related membranous nephropathy treated with radiation therapy. Intern Med. 2011;50(1):47-51

16. Sugase T, Akimoto T, Iwazu Y, et al. Minimal change nephrotic syndrome complicated with malignant ascites in a patient with type II diabetes. Intern Med. 2012;51(14):1885-1888.

17. Beck LH Jr, Bonegio RG, Lambeau G, et al. M-type phospholipase A2 receptor as target antigen in idiopathic membranous nephropathy. N Engl J Med. 2009;361(1):11-21.

18. Qin W, Beck LH Jr, Zeng C, et al. Anti-phospholipase A2 receptor antibody in membranous nephropathy. J Am Soc Nephrol. 2011;22(6):1137-1143.
19. Zhang Q, Huang B, Liu X, et al. Ultrasensitive quantitation of antiphospholipase A2 receptor antibody as a diagnostic and prognostic indicator of idiopathic membranous nephropathy. Sci Rep. 2017;7(1): 12049.

20. Ohtani H, Wakui H, Komatsuda A, et al. Distribution of glomerular IgG subclass deposits in malignancy-associated membranous nephropathy. Nephrol Dial Transplant. 2004;19(3):574-579.

21. Yamauchi H, Linsey MS, Biava CG, Hopper J Jr. Cure of membranous nephropathy after resection of carcinoma. Arch Intern Med. 1985;145(11):2061-2063.

22. Coltharp WH, Lee SM, Miller RF, Averbuch MS. Nephrotic syndrome complicating adenocarcinoma of the lung with resolution after resection. Ann Thorac Surg. 1991;51(2):308-309.

23. Ito H, Kumagai Y, Iida M, Yamazaki S, Odajima H, Kawano T. Patient with esophageal cancer showing remission of nephrotic syndrome after esophagectomy: report of a case. Surg Today. 2013;43(12):1452-1456.

24. Boon ES, Vrij AA, Nieuwhof C, van Noord JA, Zeppenfeldt E. Small cell lung cancer with paraneoplastic nephrotic syndrome. Eur Respir J. 1994;7(6):1192-1193

25. Shikata Y, Hayashi Y, Yamazaki H, Shikata K, Makino H. Effectiveness of radiation therapy in nephrotic syndrome associated with advanced lung cancer. Nephron. 1999;83(2):160-164.

26. Ishikawa G, Nishimura N, Mochizuki S, et al. Long-term survival of a patient with extensive small cell carcinoma of unknown primary etiology complicated by nephrotic syndrome. Intern Med. 2014;53(2): $159-162$.

27. Matsuura H, Sakurai M, Arima K. Nephrotic syndrome due to membranous nephropathy associated with metastatic prostate cancer: rapid remission after initial endocrine therapy. Nephron. 2000;84(1):75-78.

28. Forslund T, Kellokumpu I, Elomaa E, Arola J, Nuorva K. Remission of membranous glomerulonephritis after pancreatectomy for pancreatic neuroendocrine neoplasm - a rare coincidence. Clin Nephrol. 2011;75(Suppl 1):42-46.

29. Ponticelli C. Membranous nephropathy. JNephrol. 2007;20(3):268-287.

30. Cantrell EG. Nephrotic syndrome cured by removal of gastric carcinoma. Br Med J. 1969;2(5659):739-740.

31. Eagen JW. Glomerulopathies of neoplasia. Kidney Int. 1977;11(5): 297-303.
International Medical Case Reports Journal

\section{Publish your work in this journal}

The International Medical Case Reports Journal is an international, peer-reviewed open-access journal publishing original case report from all medical specialties. Previously unpublished medical posters are also accepted relating to any area of clinical or preclinical science. Submissions should not normally exceed 2,000 words or

\section{Dovepress}

4 published pages including figures, diagrams and references. The manuscript management system is completely online and includes a very quick and fair peer-review system, which is all easy to use. Visit http://www.dovepress.com/testimonials.php to read real quotes from published authors. 